Article

\title{
The Features of Rural Labor Transfer and Cultural Differences: Evidence from China's Southwest Mountainous Areas
}

\author{
Shaoyao Zhang ${ }^{1,2} \mathbb{D}$, Xueqian Song ${ }^{3} \mathbb{D}$, Jiangjun Wan ${ }^{4}$, Ying Liu ${ }^{1}$ and Wei Deng ${ }^{1,2,5, *}$ \\ 1 Research Center for Mountain Development, Institute of Mountain Hazards and Environment, \\ Chinese Academy of Sciences, Chengdu 610041, China; zhangsyxs@163.com (S.Z.); liuying@imde.ac.cn (Y.L.) \\ 2 School of Resources and Environment, University of Chinese Academy of Sciences, Beijing 100049, China \\ 3 School of Management, Chengdu University of Information Technology, Chengdu 610225, China; \\ sxq@cuit.edu.cn \\ 4 Department of Urban and Rural Planning, School of Architecture and Urban-rural Planning, \\ Sichuan Agricultural University, Chengdu 610041, China; wanjiangjun@outlook.com \\ 5 Chinese Science Center of the International Eurasian Academy of Sciences, Beijing 100107, China \\ * Correspondence: dengwei@imde.ac.cn; Tel.: +86-28-85353897; Fax: +86-28-8535-3897
}

Received: 28 January 2019; Accepted: 7 March 2019; Published: 13 March 2019

\begin{abstract}
Large-scale rural labor transfer is considered an important means of promoting urbanization and poverty alleviation; however, it has been difficult to fully reveal the complexity of mountain labor transfer using traditional theory. In this study, macrostatistics and microsurvey data were employed to conduct an empirical analysis of rural labor transfer in Xichang, highlighting the regional features of rural labor transfer in the southwest mountainous areas of China. The results show that the employment structure of rural labor is dominated by agriculture; however, its proportion is decreasing annually. The development of secondary and tertiary industries significantly contributes to the non-agricultural employment of rural laborers, who transfer mainly to the building, industry, and consumption fields-especially consumption, which has the greatest ability to absorb surplus rural labor. Migration of the population and farmers' per capita net income promotes rural labor transfer, while the amount of rural labor, the urbanization rate in townships, agricultural development, and the topography have lagged effects on the process. This study argues that rural labor transfer in the mountains has regionality, multi-pattern, and gradient features; therefore, the promotion of rural labor transfer should consider local urbanization and poverty alleviation in such a manner that aligns with the local natural and socioeconomic conditions of the mountainous areas.
\end{abstract}

Keywords: mountain rural labor; cultural differences; regionality; gradient transfer; China

\section{Introduction}

Rural labor transfer occurs through two processes; the transfer of industry and geographic transfer. This process includes a transfer from agricultural to non-agricultural employment, as well as a transfer of rural to urban-based labor [1]. The result of these processes is growth of the non-agricultural population and an increased rate of urbanization. The amount of agriculture employment is reduced, while employment in secondary and tertiary industries increases [2]. These two processes almost always accompany each other and occur at the same time. However, the rural labor force prefers employment transfer first and then moves to urban areas, where it has abundant employment opportunities in secondary and tertiary industries because of the spatial imbalance of employment [3]. Further, urbanization, industrial, and agricultural development affect the size and speed of rural labor transfers and urban absorption capacity regarding rural surplus labor $[4,5]$. 
Using analytical methods, scholars have indicated that adjustment in the industrial structure encourages employment transfer from agricultural rural labor to non-agricultural rural labor, and that labor transfer promotes the optimization of the industrial structure [6-8]. Although this conclusion aligns with the current rapid urbanization in China, China's rural labor transfer is more complex than that of other smaller developing countries due to considerable regional differences in urbanization and the country's enormous number of rural laborers. Therefore, there is considerable heterogeneity in the development of secondary and tertiary industries and the absorptive capacity and efficiency of rural labor among regions [2]. However, the scale differences in rural labor have not received much scholarly attention. The transfer pattern of the rural labor is diverse when workers decide to transfer, such as working part-time in a town, or transferring to a county, city, or regional metropolis $[9,10]$. In addition, rural labor transfer is not only a single flow because the outflow areas might also be inflow areas. In particular, research on the complexity of rural labor transfer in small areas has been rare. To summarize, these inferences indicate that the local and regional features of rural labor transfer should be emphasized [11].

Numerous studies have focused on labor transfer decision-making motivation and its relationship with industrial structure and economic development [2,12], confirming that the income gap, availability of public services, and the cultural environment are the main factors that draw rural labor. Rural labor transfer could significantly promote the upgrading of the industrial structure, contribute to increasing farmers' income, and stimulate social consumption, thus contributing to economic growth [13]. However, some studies have found that growth in rural transfer is not linear, with local urbanization and adjustment in the regional industrial structure likely to slow the rate of transfer. A study based on the Andes in Ecuador found that transferring rural support to hometowns to help individuals to develop small agricultural businesses through remittances reduced the possibility that the transfer of surplus labor would continue [12]. Furthermore, research on a northern Indian village found that local urbanization increased the number of short-term round-trip transfers between rural and urban areas, but this type of labor transfer is incomplete, random, and temporary [14]. Not only does labor transfer occur between net inflow areas and net outflow areas, but also other types of rural labor fills the gaps in the employment market when local rural laborers transfer to faraway urban areas [15]. Thus, regional transfer trends and the employment patterns of rural labor are very complex. As classical theory has many limitations when considering small regions or mountainous areas, studies on the regional characteristics of rural labor transfer produce more realistic results. In addition, there are few studies that have combined macro statistical data and micro questionnaire data to comprehensively interpret the transfer trends and the mechanisms driving rural labor $[8,11,16,17]$.

Based on the discussed analyses, this paper focuses on the following research issues. What are the features of rural labor transfer in mountainous area? Are the features of labor transfer in small areas consistent with those in large-scale studies? If not, why do these differences arise? What is the scientific significance of these differences in guiding poverty alleviation and new-type urbanization? Therefore, the purposes of this paper are: (1) to analyze the rural labor transfer features in mountainous regions and the cultural differences considering Xichang in China as an example; and (2) to understand the effects and adaptation strategies of regional urbanization and industrial restructuring regarding mountainous rural labor transfer. It is expected that the findings from this study will help to promote urbanization and poverty alleviation.

\section{Data and Method}

\subsection{Case Study Description}

Xichang, which is in China's southwest mountainous area, is the political, economic, cultural, and tourist center of the Liangshan Yi Autonomous Prefecture (Figure 1). Its location is $101^{\circ} 46^{\prime} \sim 102^{\circ} 25^{\prime} \mathrm{E}$, $27^{\circ} 32^{\prime} \sim 28^{\circ} 10^{\prime} \mathrm{S}$, and the Anning River flows through it. The average altitude in Xichang is approximately $2160 \mathrm{~m}$, and the mountainous region accounts for $83.6 \%$ of the total area, while the 
flat valley accounts for only $16.4 \%$. Xichang is in a tropical plateau monsoon climate zone, and it experiences hot and rainy periods resulting in highly developed agricultural production in the Anning River valley. Xichang is divided into 6 urban districts and 37 rural townships, and it had a registered population of 663.1 thousand in 2016, of whom $23.80 \%$ were minority nationalities (i.e., Yi, Hui, Tibetan, etc.). Xichang's transfer ratio of rural labor was only $23.08 \%$ in 2016, and there is still a large segment of the rural surplus labor force that urgently needs to transfer, especially from the poverty-stricken rural mountains. Meanwhile, because it has pleasant sunshine and is a lakeside city, Xichang has become a popular spot for real estate and tourism investment over the past decade. In addition, Xichang has become the second base of Panzhihua Steel Group (PSG), driving the rapid development of the manufacturing, building, and transportation industries. With a large rural labor force, varied topography, rapid economic development, and being the center city of the Panxi zone, Xichang represents an excellent study area for examining the features of rural labor transfer in mountainous areas.

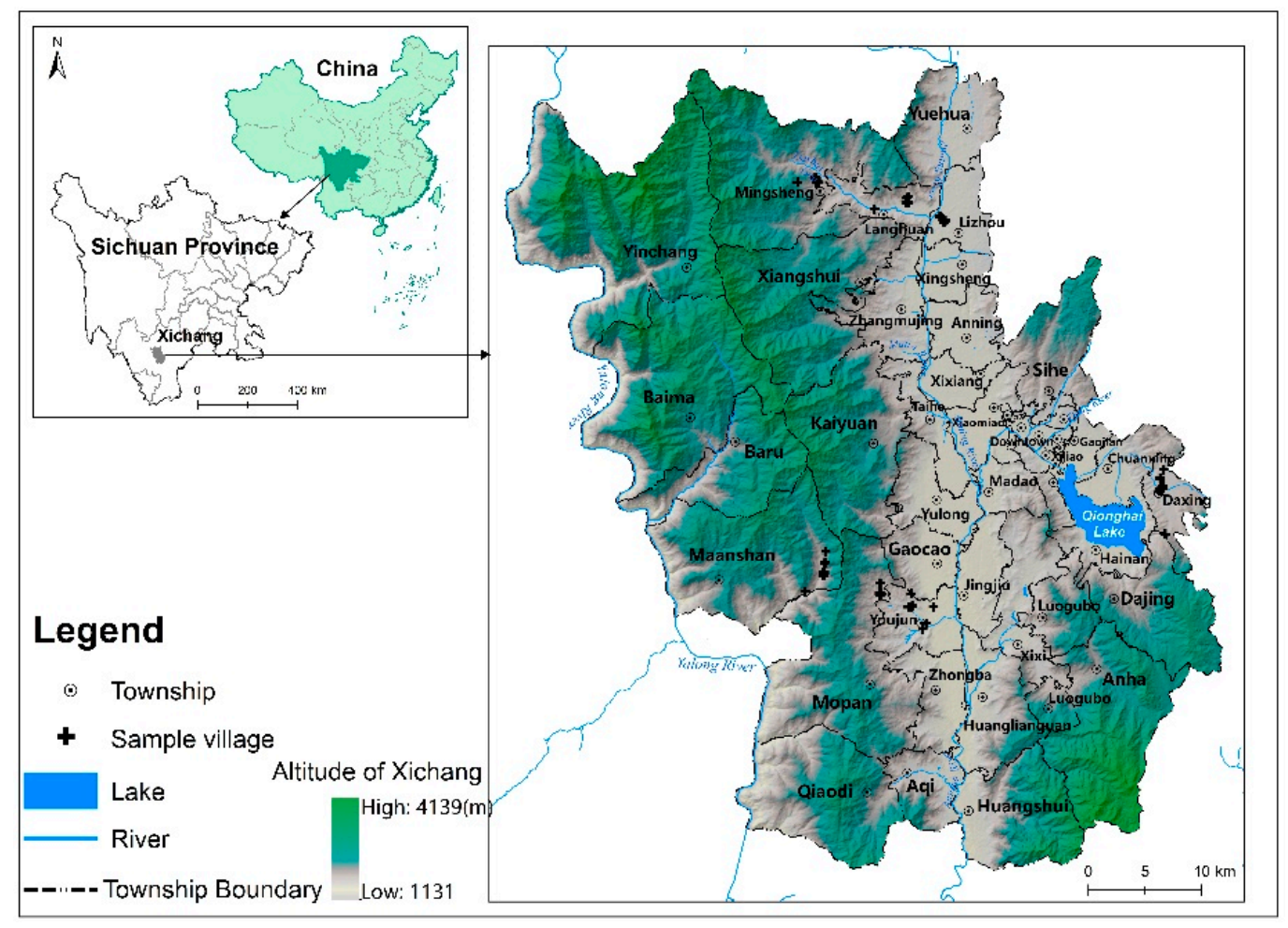

Figure 1. Overview of the study area and sample villages.

\subsection{Conceptual Framework}

In this study, the data on the number of rural laborers engaged in non-agriculture were obtained by subtracting the rural labor force engaged in agriculture from the total rural labor force. Thus, this part of rural labor represents non-agricultural rural labor in towns or outside towns, and those who are outside towns were deemed to embody the true sense of rural labor transfer [18]. It was discovered in field surveys that non-agricultural rural labor is engaged in some specific industries, e.g., government officials, doctors, artisans, etc., accounting for only a small proportion of all rural laborers in townships. The employment of these laborers is relatively fixed over time, so its influence on the transfer of rural labor is negligible. Therefore, this study assumes that the total number of rural laborers engaged in non-agriculture labor represents the transfer scale of rural labor in the townships; it is the scale of surplus rural labor, and the proportion of transferred rural labor compared with that of the total numbers of rural laborers that is considered the transfer ratio of the township. 
The analytical framework of the paper is organized as follows. First, this study analyzes the spatial distribution patterns of the population and rural labor in Xichang; the change trends of the industrial structures and employment structure of rural labor during 2006-2016 were determined, and their relationship and interaction were revealed using a scatter plot. Second, the spatial pattern, transfer proportion, and transfer trends of rural labor were visualized for a 10-year period, and some factors were selected for analysis of the factors affecting the mechanisms of rural labor transfer. Then, the transfer trends and the employment structure were analyzed from the micro perspective based on surveyed data of farmers. Finally, the characteristics of rural labor transfer in southwest mountainous areas of China were comprehensively discussed.

\subsection{Data Sources}

The data in this study includes statistical and questionnaire data. Statistical data were obtained from the Xichang Statistical Yearbook (2006-2016), and include statistical indicators by township as follows: Household registered population; Non-agricultural registered population; Registered population moving into Xichang from Sichuan province; Registered population moving into Xichang from other provinces; Registered population moving out to Sichuan province; Registered population moving out to other provinces; The amount of rural labor; The amount of rural laborers engaged in agriculture; The per capita net income of farmers; and Crop sown areas, as well as the production value and rural labor employment data of agriculture, industry, building, transportation, consumption, and other industries. Questionnaire data were obtained from structured and semi-structured interviews with farmers conducted by the research group in Xichang from October 3 to 7, 2016. Farmer household labor transfer scale, employment, arable land, and other relevant information were recorded. The villages under investigation were selected using stratified sampling, considering the distance to city, terrain, and ethnicity. In total, 116 questionnaires were randomly distributed in 7 towns in peri-urban areas, suburban areas, and the mountains (Figure 1). A total of 110 valid questionnaires were collected (Table 1). The questionnaire effective response rate was $94.83 \%$.

Table 1. Characteristics of the study villages.

\begin{tabular}{ccccc}
\hline Town & Altitude $(\mathbf{m})$ & Households Surveyed & Distance $\mathbf{( k m )}$ & Main Ethnicity \\
\hline Lizhou & 1536 & 5 & 19.7 & Han \\
Youjun & 1556 & 15 & 19.3 & Han \\
Langhuan & 1606 & 25 & 23.9 & Han \\
Daxing & 1632 & 36 & 13.6 & Han \\
Moapn & 1765 & 8 & $S_{0}$ & Yi \\
Ma'anshan & 1863 & 10 & 29.9 & Yi \\
Minsheng & 1890 & 11 & 28.9 & Yi \\
\hline
\end{tabular}

\subsection{Methods}

\section{Global Moran's I}

Global Moran's I was used to detect the spatial agglomeration of the population distribution of Xichang, as shown in Formula (2) [19]:

$$
I=\frac{n}{S_{0}} \frac{\sum_{i=1}^{n} \sum_{j=1}^{n} W_{i, j} Z_{i} Z_{j}}{\sum_{i=1}^{n} Z_{i}^{2}}
$$

where $Z_{i}$ is the deviation factor between the element $i$ and its mean $\left(X_{i}-\bar{X}\right), W_{i, j}$ is the spatial weight between $i$ and $j, n$ is the total number of elements, and $S_{0}$ is the aggregation of all the spatial weight $\left(S_{0}=\sum_{i=1}^{n} \sum_{j=1}^{n} W_{i, j}\right) . I>0$ represents spatial concentration, $I<0$ represents spatial dispersion, and $I=0$ represents the spatial random. 


\section{Results}

\subsection{Spatial Distributions and Changes in the Population of Xichang}

In 2016 in Xichang, the total registered population was 663,100 people. The permanent resident population was 775,000 people, the floating population reached 111,900, accounting for $14.44 \%$ of the permanent resident population, and the urbanization rate was 57.57\%. From 2006-2016, Xichang had a net inflow of population area, showing an overall increasing trend in the floating population, but there were decreases in 2007-2009 (Figure 2). The total increase in the floating population of Xichang was 47,300 over 10 years with an average annual growth rate of $7.32 \%$. Figure 2 shows that the registered population growth was steady from 2006-2016, but the resident population rapidly grew over the period of 2009-2011 because of the return of rural migrant workers from eastern cities, tourism development in Xichang, and immigrants from the hydropower project. These findings illustrate that changes in the population of Xichang were not simply the result of natural growth but of urbanization, rural labor transfer, and other causes.

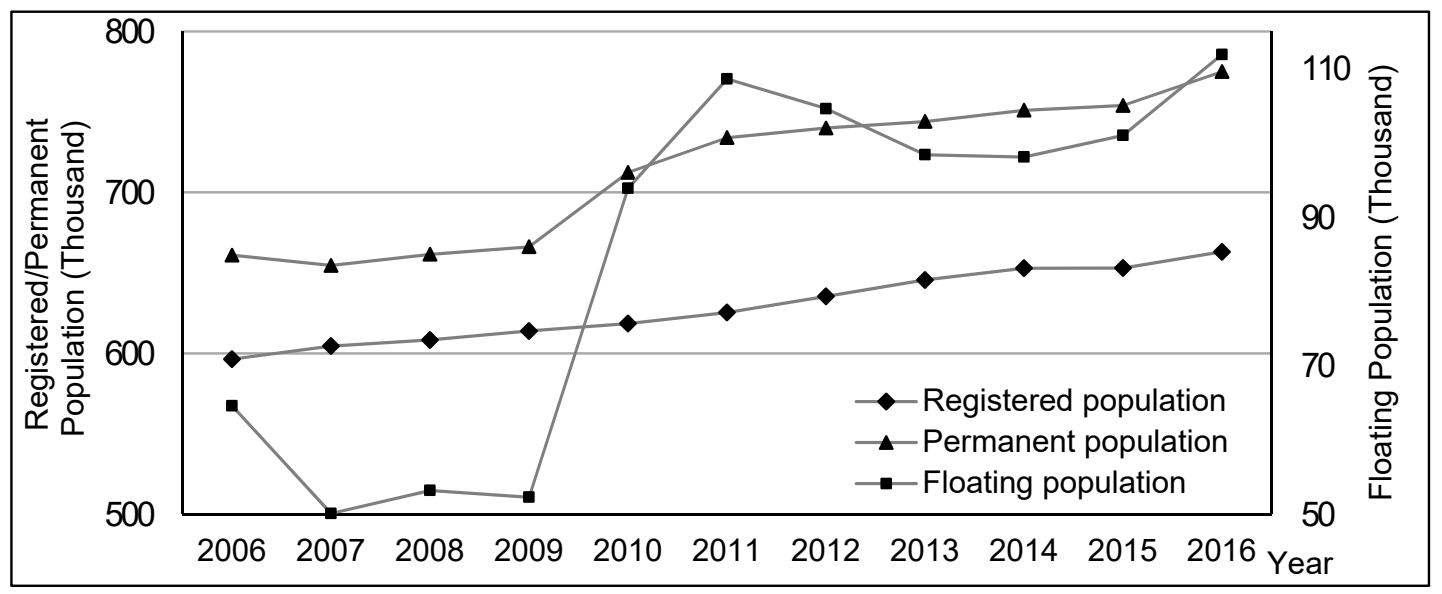

Figure 2. The change trends of population in Xichang over the period of 2006-2016.

Figure 3 shows the spatial pattern of registered population density and its change in townships from 2006-2016, during which the main population centers were in the Anning River valley and the Qionghai Lake basin. The Qionghai Lake basin, located near the urban area, is also the city's most populated area. The Anning River valley is the most important farming area, with a flat, open terrain beneficial to the large-scale mechanization of agriculture. The Yak Mountain in the west and the Luoji Mountain in the southeast of Xichang both have rugged terrain and low population density and are the main areas where ethnic minorities agglomerate. Global Moran's I was used to measure the spatial autocorrelation of population density from 2006-2016 (Table 2), and the results showed that the spatial distribution of the population indicated an agglomeration trend in Xichang, where overall, the degree of concentration increased from 2006-2016. In terms of the townships, the most significant growth areas were downtown areas and along both sides of the Anning River; in particular, its increase in population was also significantly greater than that of the valley area. In summary, while the total population and the floating population increased, the spatial distribution of the population also showed agglomeration trends flowing towards urban areas. 

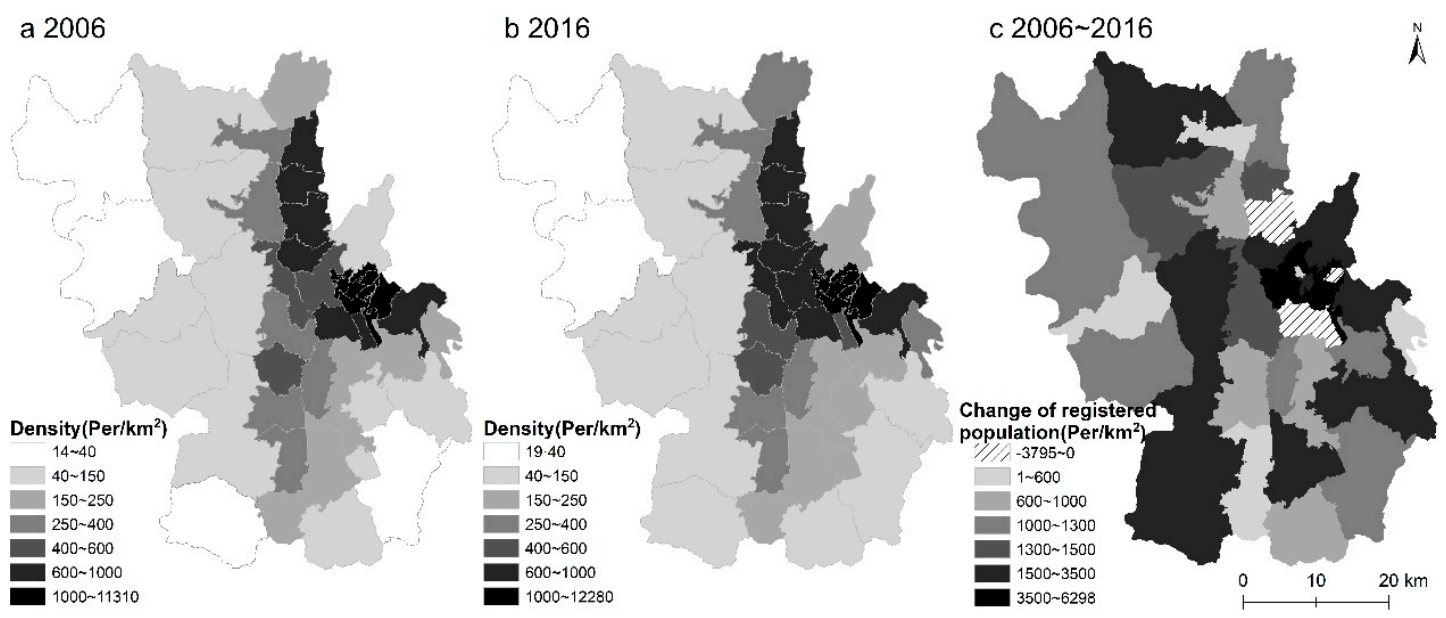

Figure 3. Registered population density (a,b) and the change in the registered population (c) in 2006-2016.

Table 2. Spatial autocorrelation of the population density in Xichang in 2006-2016.

\begin{tabular}{cccccc}
\hline Year & Moran's $\boldsymbol{I}$ & $\boldsymbol{p}$ & Year & Moran's $\boldsymbol{I}$ & $\boldsymbol{p}$ \\
\hline 2006 & 0.6247 & 0.00 & 2011 & 0.6341 & 0.00 \\
2007 & 0.6359 & 0.00 & 2012 & 0.6441 & 0.00 \\
2008 & 0.6355 & 0.00 & 2013 & 0.6437 & 0.00 \\
2009 & 0.6361 & 0.00 & 2014 & 0.6426 & 0.00 \\
2010 & 0.6353 & 0.00 & 2015 & 0.6421 & 0.00 \\
& & & 2016 & 0.6423 & 0.00 \\
\hline
\end{tabular}

\subsection{Changes in the Employment Structure of Rural Labor}

Xichang, with a GDP of 45.72 billion yuan, which increased by $6.30 \%$, is the center of the Panxi Economic Area. The contributions of primary, secondary, and tertiary industry to GDP are $9.41 \%$, $49.48 \%$, and $41.11 \%$, respectively. In terms of change trends, the share of agriculture decreased yearly from $15.68 \%$ to $9.74 \%$ from $2006-2016$, representing a decrease of $36.67 \%$. Other services and consumption services underwent different degrees of decline, while the proportion of transportation, building, and industry increased significantly (Figure 4). After the Wenchuan earthquake in 2008, the central government invested heavily in rebuilding and upgrading the infrastructure in the western mountainous areas of Sichuan to repair the damage caused by the earthquake, leading to a rapid increase in investment in the transportation industry. While the industrial sector in Xichang suffered minor damage from the quake and recovered quickly in 2009, it leads to an increase in transportation and an opposite decrease in the industrial sector in 2008. In summary, between 2006 and 2016, the proportion of secondary industry increased by $6.83 \%$, while agriculture experienced a decline of $5.95 \%$. The service sector decreased slightly by $0.88 \%$. These results show that Xichang is undergoing a process of transition from an agriculture-based economy to an industrial-based economy; industry and building have played increasingly important roles in promoting the economic development of Xichang.

In 2006, there were 237,200 rural laborers. This number increased to 261,500 by 2016, representing an increase of $10.26 \%$. In terms of the employment structure of rural labor, agriculture has been the preferred choice, although its proportion declined from $81.68 \%$ in 2006 to $76.67 \%$ in 2016, representing a decrease of $6.13 \%$ (Figure 5). At the same time, the proportion of rural laborers engaged in consumption and building has increased significantly. In particular, consumption experienced a growth of $57.41 \%$, indicating the engagement of rural labor in wholesale and retail trade, as well as accommodation and catering, which have increased considerably. Although the proportion of rural laborers engaged in industry and the transportation sector has also increased, its growth rate was lower than that of the consumption fields and building. All of these findings inferred that most recent rural 
laborers transferred to non-agriculture, namely, transferring to the secondary and tertiary industries, representative of the employment trend for the past 10 years.

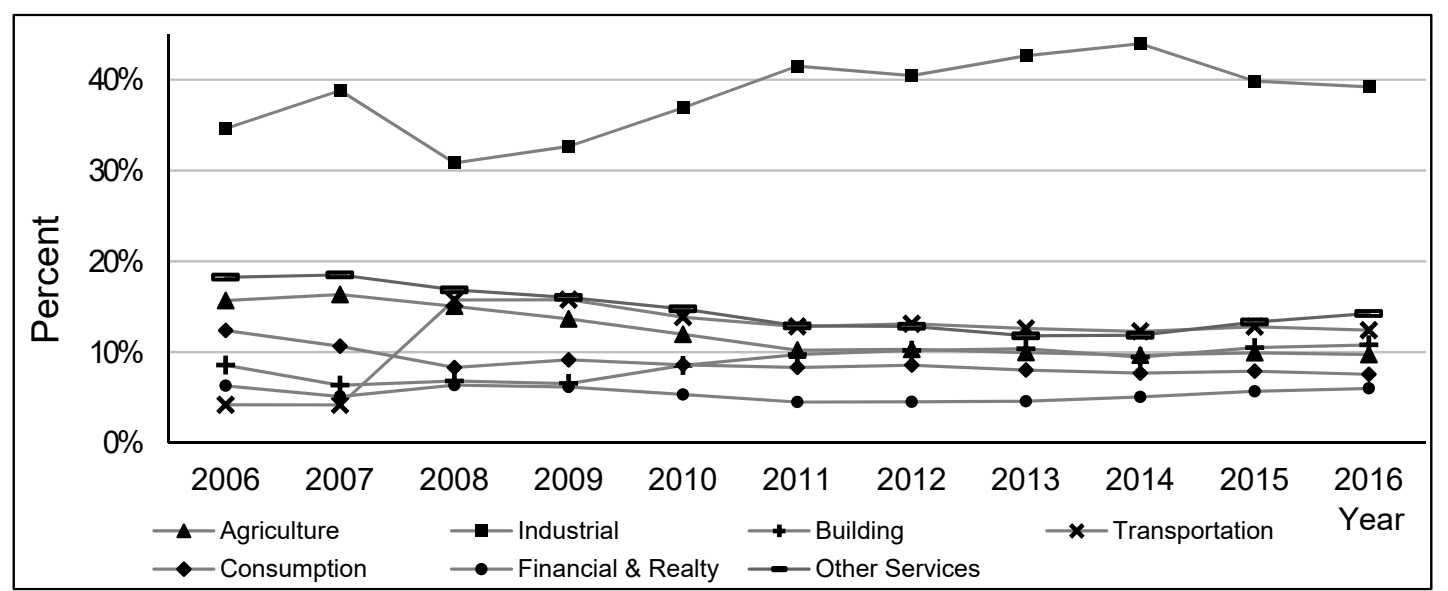

Figure 4. Change trends of industrial share to GDP for the period of 2006-2016.

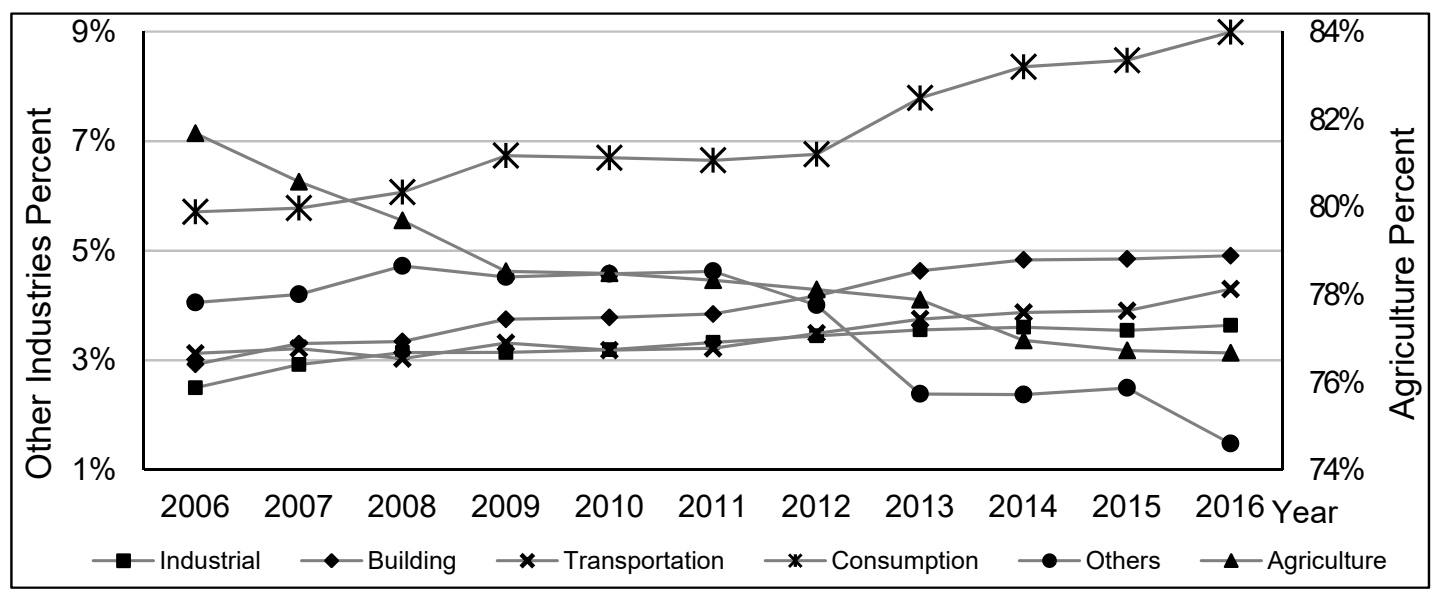

Figure 5. The change tends of the rural laborers' employment structure of in Xichang.

The ratios of the agriculture, industry, building, transportation, consumption, and other services to GDP were calculated; these ratios are represented by Agr/GDP, Ind/GDP, Bui/GDP, Tran/GDP, Con/GDP, and $O t h / G D P$, respectively. The ratio of these fields to the total number of rural laborers is represented by Agr_labor, Ind_labor, Bui_labor, Tran_labor, Con_labor, and Oth_labor, respectively. Regression analysis indicates that there is a linear relationship between the industrial structure $(x)$ and the rural labor employment structure $(y)$, and the results show that the proportions of agriculture, industry, building, and consumption in the industrial structure significantly correspond with their employment proportions $(p<0.05)$ (Figure 6$)$, while those of the transportation and other services are weak. Agr/GDP with Agr_labor have a significantly positive correlation $(p<0.01)$. This result shows that for each $1 \%$ decrease in the ratio of agriculture to the GDP, there was a $1.5053 \%$ transfer to non-agriculture employment among rural laborers, indicating that the decline in the proportion of agriculture in the industrial structure increased rural labor transfer to non-agricultural industries.

Although Ind/GDP and Bui/GDP gradually increased, the attracted rural labor decreased annually. In contrast, the share of the consumption in GDP rapidly decreased yearly, while the gross and increase in attracted rural labor were more than industry and building (Figures 4-6), so their absorptive efficiency of surplus rural labor was the highest. The absorption efficiency of building for rural surplus labor was higher than that of industry. Women accounted for $57.45 \%$ of the added surplus rural labor force; the proportion of women in the total rural labor force increased from $48.15 \%$ to $49.01 \%$ from 
2006-2016. Although there were fewer woman than men, the women's growth rate was significantly higher than that for men. Moreover, the additional rural laborers who engaged in consumption accounted for $64.21 \%$ of all of the added rural surplus labor, while those that chose building accounted for only $24.29 \%$. Therefore, it can be inferred that more rural female laborers were more likely to choose consumption and men chose building. In short, the relative weakening of agriculture and the relative growth of the secondary and tertiary industries represent the push and pull power of rural labor transfer, and it is proven that the change in the industrial structure promoted the transformation of the employment structure of rural labor.
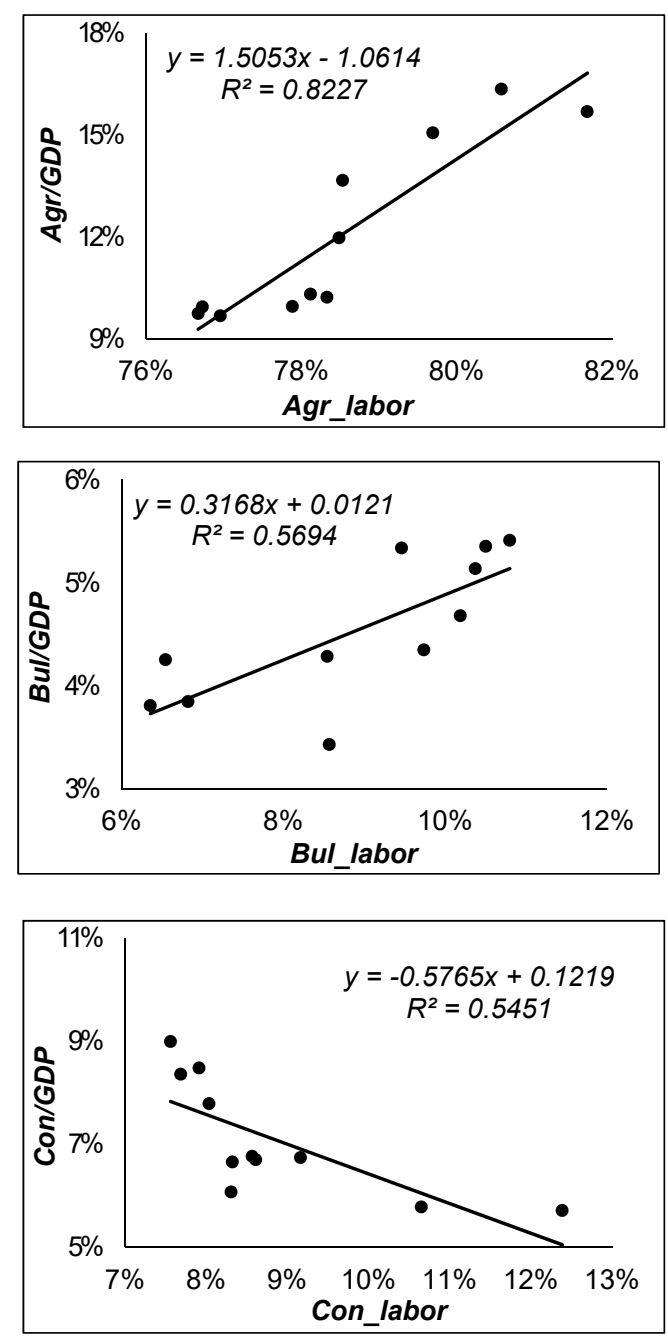
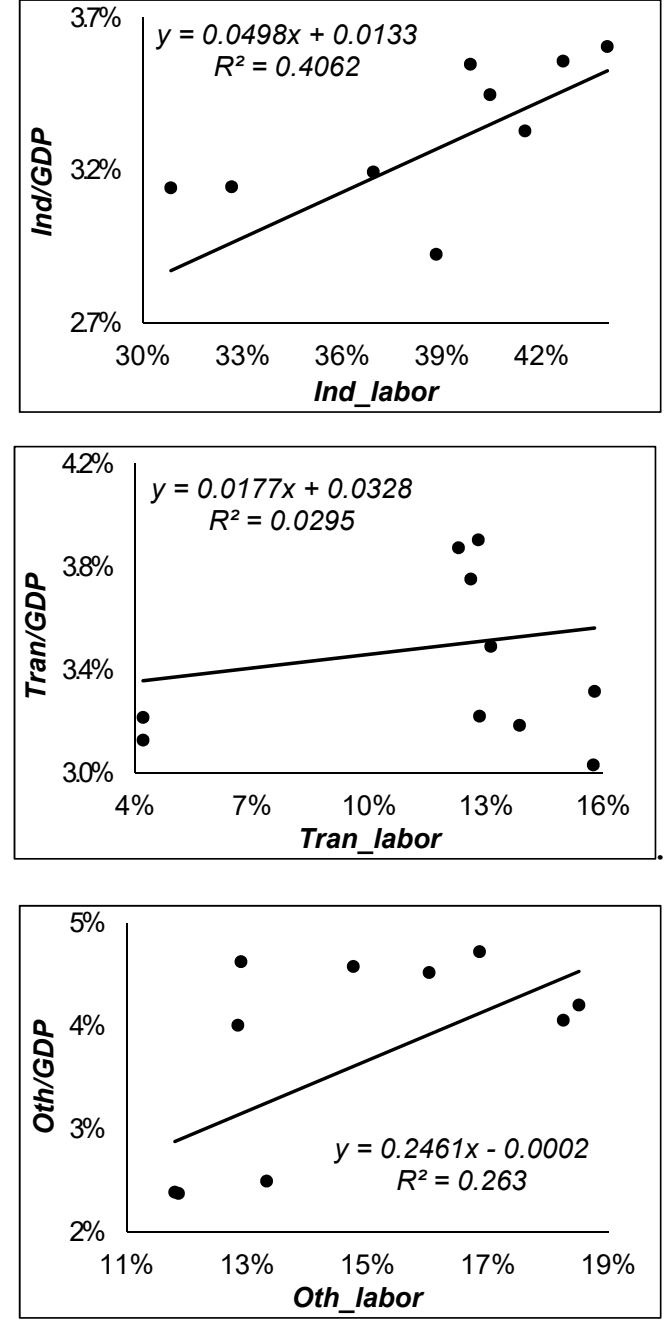

Figure 6. The relationship between the industrial share of GDP and the employment structure of rural labor.

\subsection{Changes in the Spatial Patterns of Rural Labor Transfer}

Figure 7 shows that the ratio for the spatial pattern and rural labor transfer in 2016 and the rural labor in the Anning River valley are similar to the pattern of population density in Xichang (Figure 3b). The amount of rural labor in the western and southeast mountainous areas is relatively small, especially in Yinchang township, which has a rural labor population of only 1414 people, representing $9.07 \%$ of Xingsheng, and it is the township with the most rural labor. The townships with the highest rural labor transfer ratio are in the surrounding urban areas (i.e., Gaojian, Hainan, Taihe, Xiaomiao, Madao, etc.), indicating that urbanization can promote rural labor transfer. Among these townships, another common feature is the relatively small number of rural laborers (i.e., Madao, Hainan, etc.), while townships with more rural laborers have a lower transfer ratio than the other townships (i.e., Yuehua, Lizhou, etc.). 

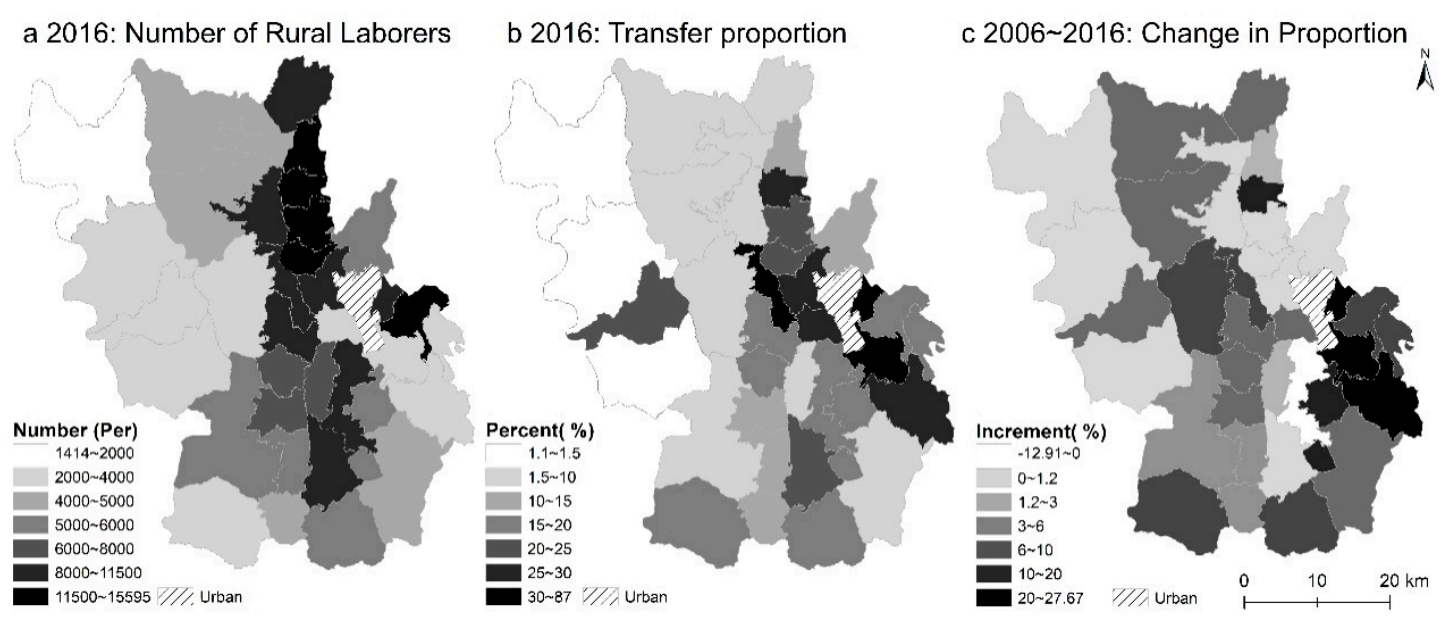

Figure 7. Spatial distribution pattern (a) of rural labor and its transfer ratio (b) and trends (c).

Compared with the changing trend in the rural labor transfer ratios of towns from 2006-2016, almost all of the townships increased by varying degrees, except for Xixi, which decreased by $12.91 \%$. The most significant growth occurred in the Qionghai Lake basin (i.e., Gaojian, Hainan, etc.), indicating that these towns were affected by the urbanization of Xichang. From 2006 to 2016, the rural labor transfer ratio of the river valley, which had more laborers, was lower than that of the non-valley areas. That is, the thrust of the transfer in valley townships that had relatively developed agriculture and had more rural laborers was weaker than that of towns that had relatively underdeveloped agriculture and had mountainous terrain, which may indicate that the development of agriculture affects the transfer of rural surplus labor. However, there are exceptions in the Yi ethnic habitat (i.e., Yinchang, Baima, $M a^{\prime}$ anshan). Although there was less rural labor, the transfer ratio and its growth rate were low.

\subsection{Factors Affecting the Transfer of Rural Labor}

This study uses the Ratio of rural labor transfer as the dependent variable (y), and Number of rural laborers (x1), Urbanization rate in township (x2), Crop acreage (x3), Registered population emigration rate (x4), Registered population immigration rate (x5), Per capita net income of farmers (x6), and Topographic relief (x7) as independent variables. The panel data include 37 townships from 2006 to 2016. The results of multiple linear regression are shown in Table $3, R^{2}=0.836(F=235.802$, $p<0.01)$ indicates that the results are significant. We find that $\mathrm{x} 1, \mathrm{x} 2, \mathrm{x} 3, \mathrm{x} 5, \mathrm{x} 6$, and $\mathrm{x} 7$ have significant effects $(p<0.10)$ on the Ratio of rural labor transfer, especially $x 1, x 6$, and $x 7(p<0.01)$. In addition, $x 4$, $\mathrm{x} 5$, and $\mathrm{x} 6$ are driving factors, while $\mathrm{x} 1, \mathrm{x} 2, \mathrm{x} 3$, and $\mathrm{x} 7$ are hindering factors.

Table 3. Linear regression test statistics for the ratio of rural labor transfer.

\begin{tabular}{ccccc}
\hline Variables & Parameter Estimation & Standard Coefficient & $t$ & $p$ \\
\hline Constant & 0.287 & $/$ & 9.617 & $0.000^{* *}$ \\
Number of rural laborers $(x 1)$ & -0.450 & -0.561 & -13.256 & $0.000^{* * *}$ \\
$\quad$ Urbanization rate in & -0.067 & -0.055 & -1.805 & $0.072^{*}$ \\
$\quad$ township $(x 2)$ & -0.069 & -0.093 & -3.020 & $0.003^{* * *}$ \\
$\quad \begin{array}{c}\text { Crop acreage }(x 3) \\
\text { Registered population } \\
\text { emigration rate }(x 4)\end{array}$ & -0.020 & 0.020 & 0.693 & 0.488 \\
$\begin{array}{c}\text { Registered population } \\
\text { immigration rate }(x 5)\end{array}$ & 0.034 & 0.040 & 1.657 & $0.098^{*}$ \\
$\begin{array}{c}\text { Per capita net income of } \\
\text { farmers }(x 6)\end{array}$ & 0.168 & 0.203 & 4.561 & $0.000^{* * *}$ \\
Topographic relief $(x 7)$ & -0.290 & -0.358 & -0.827 & $0.000^{* * *}$ \\
\hline
\end{tabular}

Note: ${ }^{*}, * * * *$ indicate statistical significance at the $10 \%, 5 \%$, and $1 \%$ level, respectively. 
The results show that compared to townships with fewer rural laborers, townships with a large rural labor force in the river valley have agriculture that is relatively developed (Figure 7), and their agriculture departments can provide sufficient employment opportunities and expectant incomes for rural labor, thus reducing the ratio of rural labor transfer. Similarly, a larger scale of crop acreage indicates that there is great agriculture potential and the towns make good profits, so they can also better absorb rural labor, causing the willingness of rural laborers to transfer to non-agriculture to decrease. The higher the urbanization rate in townships is, the less rural surplus labor there is and the more off-farm employment opportunities there are, so local urbanization in townships can reduce the rural labor transfer to outside the townships, such as to metropolitan areas. Moreover, the demand for urbanization regarding agriculture increases the profits and efficiency of agricultural production and reduces the transfer willingness of rural surplus labor. However, the significance of Urbanization rate in township is inferior to Number of rural laborers and Crop acreage (absolute value coefficient and significance) (Table 3). The natural resources and geographical conditions of the townships with greater topographic relief are more difficult, and they are the main habitats of the Yi ethnic group. The field survey showed that due to the barriers of traffic, education, and language and issues regarding employment, rural mountain laborers rarely transfer outside these areas. If they must transfer because of livelihood, they are more likely to move to the valley township to find agricultural employment rather than off-farm employment. This transformation is temporary and unsustainable, and it also reflects the difficulty and peculiarity of the mountainous ethnic minorities in rural labor transfer.

The Per capita net income of farmers directly reflects the wealth of rural labor. According to Lewis' dual structure theory, the marginal revenue of non-agriculture is higher than that of agriculture due to urbanization, so higher incomes will further stimulate rural labor transfer to non-agriculture and more laborers will refuse to return to agriculture. Registered population immigration $(x 5)$ and emigration rates $(x 4)$ reflect the scale of population migration, but the latter's influences are not significant. Compared to population emigration, registered population immigration better promotes the transfer of rural surplus labor to other areas. Since 2009, most poor migrants have moved to rural areas and were allocated arable land and housing because of the hydropower station building in Xichang, which was how a major part of the registered population moved into the townships, and formed a base of competition for jobs with local rural labor, resulting in the original rural surplus labor transferring to non-agriculture employment. Currently, in the social context of China, registered population emigration and transfer hukou occur primarily due to education, systematic employment, or marriage. It is difficult for rural laborers to move their agriculture hukou to the city without housing or systematic work in urban areas, so registered population emigration has a weak impact on rural labor transfer.

\subsection{Microempirical Analysis of Rural Labor Transfer}

The results of the survey questionnaire show that there is transferred labor in $81.00 \%$ of 110 surveyed rural households; $1,2,3$, or more laborer transfers in each household accounted for $25.00 \%$, $37.50 \%$, and $18.75 \%$, respectively (Figure 8 ). In addition, we found that $6.25 \%$ of the part-time households do not have transferred labor in the survey, but the main home laborers have 3 or 4 months of work experience in non-agriculture near the towns when it is the quiet season (seasonal or short-term transfer). The remaining $12.00 \%$ of the households without transferred labor are full-time farmers. Of the rural laborers who have transferred, $46.43 \%$ transferred to the building field, $20.31 \%$ to industry, $32.14 \%$ to consumption, and the remaining $0.12 \%$ to other fields. Among these workers, $64.29 \%$ are male rural laborers, $100 \%$ of the laborers who transferred to building are male, and $62.50 \%$ of laborers who transferred to industry are male. Women account for $77.78 \%$ of the laborers who transferred to consumption. Furthermore, we found that households with no transferred labor have 0.36 ha of arable land on average, while households with transferred labor have 0.28 ha. Households with 1 member who transferred have 0.37 ha of arable land on average, those with 2 members who transferred have 0.29 ha, and those with 3 or more members who transferred have only 0.16 ha. 


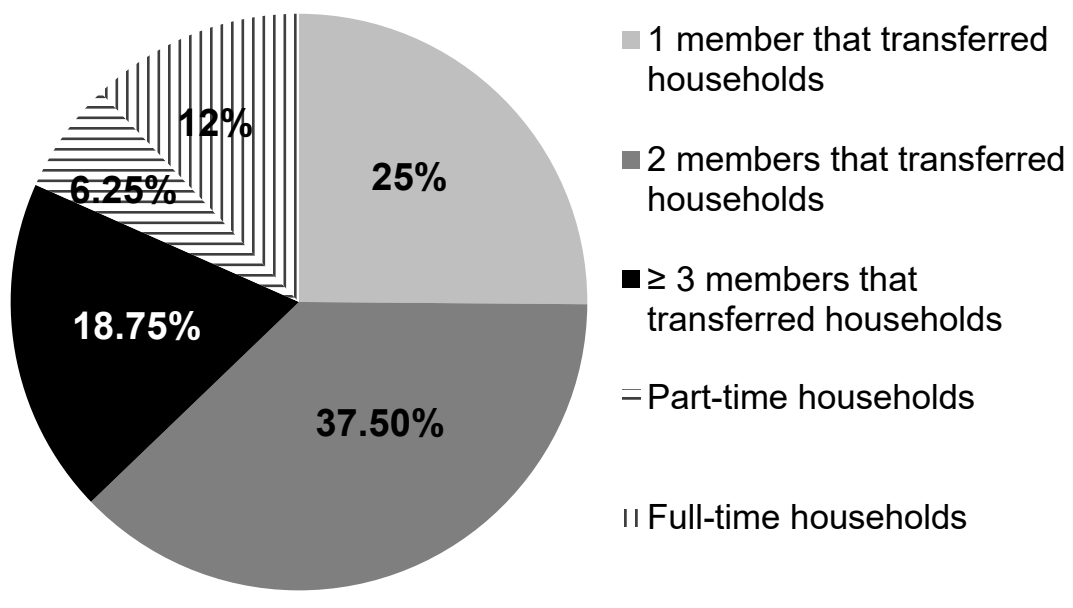

Figure 8. Proportions of the different transfer types of in the surveyed households.

The survey data indicate that $42.86 \%$ of the total rural laborers and $81.00 \%$ of surveyed households select non-agriculture employment. There is a clear employment structure; that is, rural labor generally transfers to the building, industrial, and consumption sectors, and male rural labor prefer the building and industrial sectors, while women prefer the consumption sector. Further, it is proved that gender differences can affect the differentiation of the employment structure of rural labor. Men are the pioneers of transferred rural labor because of their adventurous and physical advantages. However, within the development of the tertiary industry (i.e., consumption), women are also employed in non-agriculture, along with transferred male laborers, thereby promoting family transfer and urbanization or citizenization.

Regarding this context in Section 3.2, we find that the employment structure of rural labor gradually transitions from being primarily agriculture-based to off-farm employment step by step, and now it is in the phase of transitioning from being agriculture-based to including both agriculture and non-agriculture, indicating a change from an agricultural society to an industrial society, which is an important reason for the short-term and round-trip transfer of rural labor in China today. In particular, transferred farmers have not completely abandoned agriculture, but its scale will gradually decrease with the expansion of transfer $[3,20]$. This relationship can be understood in two aspects; first, rural households must transfer to non-agriculture due to less originally owned arable land; and second, rural households are unable to continue farming their original farmland because of a large number of transferred laborers and have to rent or give farmland to others.

\section{Discussion}

\subsection{Regionality of Rural Labor Transfer}

At the global or national scale, rural labor transfer is in line with classical theory. However, in regions or smaller areas, the regional features and cultural differences of rural labor transfer are more significant. The case study of Xichang shows that agricultural development, urbanization in townships, and the terrain slow rural labor transfer, but the results differ from results based on large-scale study areas [21]. However, many studies have proved that the drivers of rural labor transfer include the urban-rural income gap, public services, and the cultural context, among others. There is no denying that high revenue is the initial motivation for most rural laborers. That is, employment transfer is prioritized over regional transfer, especially in China, which is a developing country undergoing rapid urbanization [22]. If workers' income is less than or not significantly greater than their original incomes, then their transfer behavior is pointless [23]. Therefore, if the existing employment opportunities and income levels in rural areas or townships can meet their income expectations in the townships, the proportion and willingness of rural laborers' transfer will be reduced [3]. 
The above inferences can be compared and discussed with the study of the Ecuadorian Andes [12]. Migrant remittances support smallholder agricultural development in mountain areas, thereby reducing the willingness of rural laborers to transfer. The same phenomenon often occurs in Xichang (Figure 9); the initial transferred rural labor significantly increases the incomes of rural households to improve living standards, and increases agricultural investment. By purchasing agricultural machinery, increasing amounts of chemical fertilizer, and expansion of arable land, the remaining laborers' willingness to transfer is greatly reduced [11,17,24]. Although farming production has expanded, it does not necessarily require laborers who have transferred to urban areas to return to their hometown (occasionally), but more so it is mountainous rural surplus labor (e.g., Yi ethnic rural labor) (Figure 9). Therefore, the transfer proportion of rural surplus labor is limited in the mountains. In short, small-scale studies have shown that the galvanizing impact of the initial labor transfer on the subsequent continued labor transfer is not as significant as in the large-scale studies.

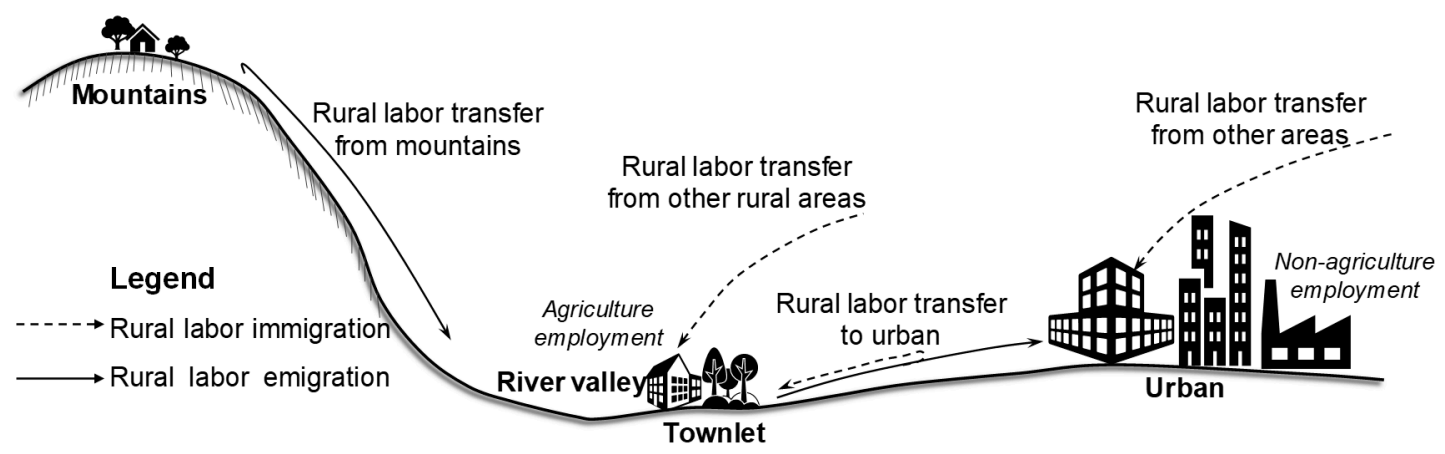

Figure 9. Sketch map of the regionality, multi-pattern, and gradient of rural labor transfer in mountains.

\subsection{Multi-Pattern of Rural Labor Transfer}

Most rural households (81.25\%) send some local laborers (mainly young) to transfer to non-agricultural employment, while the remaining laborers remain in agriculture (Figure 8). There are differences in the scale of rural labor transfer; these differences are reflected in the short-term (seasonality) and round-trip transfers of rural laborers, but this phenomenon is not only common in China but also in India [14,15], Nicaragua, and Peru, in addition to other developing countries [25]. Studies have argued that lower urbanization cannot provide an adequate number of off-farm jobs and expected income for rural labor, so the laborers who stay in agriculture guarantee their families' livelihoods. Facing underemployment, flexible labor markets, uncultured labor skills, and a dearth of public services and social security, the opportunity costs and risks faced by transferring laborers are enormous when they completely abandon agricultural production, and transfer to uncertain off-farm job markets. Thus, short-term, round-trip, or seasonal transfer (part-time rural households) of rural labor have become their best choice (Figure 8) [1,26].

The influences of topography on rural labor transfer are more complicated (Figure 9). By comparing the mountainous regions, the plains, and the hilly rural areas, one study found that early migrant remittances promoted agricultural production only in the plains and hilly rural areas, and not in the mountains [21]. Household incomes of farmers in the mountains were difficult to increase through labor transfer; rural labor transfer was more likely to result in poverty and an excessive reduction in labor. The migrant remittance in the mountainous areas did not increase investment in agriculture, so the mountainous agriculture was less attractive to local laborers than that in the plains areas, thus, these laborers were more likely to transfer. However, this conclusion is obviously substandard, possibly because the study was carried out at the inter-provincial level. This study in Xichang finds that although the transfer scale and proportion of rural labor in mountainous areas are lower than those in river valley townships, their growth rates were faster than those in river 
valley towns from 2006-2016 (Figure 7). Field research has found that barren and limited arable land and poverty do not affect large-scale labor transfer from mountains as we expected. Instead, the reclamation of farmland increases family laborers or transfers to river valley towns for temporary agricultural jobs. The rural surplus labor in the mountains has transferred mainly to become hired labor in river valley towns (Figure 9), but this temporary, flexible transfer is far from a large-scale rural labor transfer, which can result from urbanization and industrialization.

\subsection{Gradient Transfer of Rural Labor}

The negative impact of topography on rural labor transfer explains the hindrance of geographical context, reflected in the obstruction of traffic, education, labor skills, and misinformation. Therefore, the proportion and scale of rural labor transfer in the river valley are higher than that in the mountains and higher in areas with improvement of household incomes [1,21]. This paper argues that rural labor transfer is a gradient and progressive process among different occupations and regions (Figure 9) [27-29]. In addition to physical fitness, these laborers' education, labor skills, and social relationships are greatly required for the transfer of rural labor, and these qualities are progressively cultivated, so rural laborers must gradually adapt to the transition from agriculture to non-agricultural employment. This transition shows that rural laborers prefer closer transfer destinations in the initial period and jobs that are similar to their initial jobs. In addition, the transfer pattern has also been impacted by this transition process. In the initial period, rural laborers prefer close and short-term transfers and then prefer farther and longer-term or even permanent transfers in later periods, with a more optimized and advanced employment structure [28]. Rural laborers in the mountains transfer to large-scale agricultural production in the river valley in the initial stage, where the costs and risks are lower (Figure 9). Compared to the river valley, the quality, informatization, and psychological preparation of mountainous rural laborers are small and cannot complete large-scale transfers. However, mountainous regions gradually release rural surplus labor with the development of urbanization and industrialization.

\section{Conclusions}

Integrated with statistical data and survey data, this paper explains the characteristics of rural labor transfer in the southwest mountainous areas of China. The main findings are as follows. (1) The agricultural employment proportion of rural labor decreased, while secondary and tertiary industries increased yearly during the period of 2006-2016, of which the absorbing efficiency to rural labor of the consumption field is highest. (2) In off-farm employment, male rural laborers prefer the building sector, while female laborers prefer the consumption field. (3) The proportion and scale of rural labor transfer in the river valley are higher than those in the mountains, while the growth rate is lower than that in the mountains. (4) The number of rural laborers, the urbanization rate in townships, crop acreage, and topography reduce rural labor transfer, while registered population emigration and farmers' income promote rural labor transfer.

Rural labor transfer can be considered as the re-optimization of urbanization and industrialization regarding local labor resources; these impacts are the results of geographical dispersion, resulting in the gradient transfer of rural labor. The diversity and multiscale nature of geographical areas results in regionality and multi-patterns of rural labor transfer. Therefore, regionality, multi-pattern, and gradient features form the features and cultural differences of the mountain area's rural labor transfer, resulting in the differences between large-scale and small-scale studies of rural labor transfer. The regional features and cultural differences have profound impacts on the geographical landscape of rural labor in different geomorphic regions, and these differences affect not only agriculture, transportation, information availability, the availability of public service, and other aspects, but also psychological preparation, social relations, and the temperaments of different ethnicities. Thus, the local natural and socioeconomic conditions should be considered in guiding poverty alleviation and new-type urbanization. However, due to limited data and workloads, our study failed to select a larger research 
area and more questionnaire samples to further analyze the role of farmer household behaviors in the characteristics of mountainous rural labor transfer. Therefore, future research should focus on concrete expressions and connotations of rural labor transfer characteristics in the mountains.

Author Contributions: Conceptualization, S.Z., X.S., and W.D.; data curation, S.Z., J.W., and Y.L.; formal analysis, S.Z.; investigation, X.S. and Y.L.; supervision, W.D.; visualization, S.Z.; writing-original draft, S.Z.; writing-review and editing, S.Z., X.S., J.W., Y.L., and W.D.

Funding: This research was funded by the National Natural Science Foundation of China (Grant NO. 41471469, 41601141), and the Science and Technology Service Network Initiative (STS program, No. KFJ-STS-QYZD-060).

Acknowledgments: We thanks to the students from Chengdu University of Information Technology who participated in the survey and the kind local villagers who were willing to be interviewed by us. We would like to thank the two anonymous reviewers for constructive comments leading to significant improvement of this article.

Conflicts of Interest: The authors declare no conflicts of interest.

\section{References}

1. Li, Y.; Jia, L.; Wu, W.; Yan, J.; Liu, Y. Urbanization for rural sustainability-Rethinking China's urbanization strategy. J. Clean. Prod. 2018, 178, 580-586. [CrossRef]

2. Di, J.; Li, Y. Rural labor transfer mode and regional nonequilibrium degree comparative study in Shandong and Henan provinces. China Population. Resour. Environ. 2008, 18, 189-193.

3. Prifti, E.; Estruch, E.; Daidone, S.; Davis, B. How much is too much: Does the size of income support transfers affect labor supply? J. Policy Model. 2018. [CrossRef]

4. Chen, C.; Zhao, M. The undermining of rural labor out-migration by household strategies in China's migrant-sending areas: The case of Nanyang, Henan Province. Cities 2017, 60, 446-453. [CrossRef]

5. Liu, X. Empirical research on the mechanisms of migration of rural laborers from Ningxia hui autonomous region. Rev. Black Politics Econ. 2013, 40, 299-314.

6. Roberts, K.D. Agrarian structure and labor mobility in rural Mexico. Popul. Dev. Rev. 1982, 8, $299-322$. [CrossRef]

7. Qi, Y.; Tang, C. Effect of labor migration on cultivated land planting structure in rural China. Trans. Chin. Soc. Agric. Eng. 2017, 33, 233-240. (In Chinese)

8. Xie, H.; Lu, H. Impact of land fragmentation and non-agricultural labor supply on circulation of agricultural land management rights. Land Use Policy 2017, 68, 355-364. [CrossRef]

9. Qin, H.; Liao, T.F. Labor out-migration and agricultural change in rural China: A systematic review and meta-analysis. J. Rural Stud. 2016, 47, 533-541. [CrossRef]

10. Meng, L.; Zhao, M.Q. Permanent and temporary rural-urban migration in China: Evidence from field surveys. China Econ. Rev. 2018, 51, 228-239. [CrossRef]

11. Xu, D.; Guo, S.; Xie, F.; Liu, S.; Cao, S. The impact of rural laborer migration and household structure on household land use arrangements in mountainous areas of Sichuan province, China. Habitat Int. 2017, 70, 72-80. [CrossRef]

12. Gray, C.L.; Hunter, L.M. Rural out-migration and smallholder agriculture in the southern Ecuadorian Andes. Popul. Environ. 2009, 30, 193-217. [CrossRef]

13. Ming, Z. Economic impact of rural to urban labor migration in China from 1991 to 2011. China Popul. Today 2014, 24, 43 .

14. Coffey, D.; Papp, J.; Spears, D. Short-term labor migration from rural north India: Evidence from new survey data. Popul. Res. Policy Rev. 2015, 34, 361-380. [CrossRef]

15. Amaresh, D.; Richard, P.; Kunal, S. Surplus labor, social structure and rural to urban migration: Evidence from Indian data. Eur. J. Dev. Res. 2006, 18, 86-104.

16. Su, Y.; Tesfazion, P.; Zhao, Z. Where are the migrants from? Inter-vs. intra-provincial rural-urban migration in China. China Econ. Rev. 2018, 47, 142-155. [CrossRef]

17. Wan, J.; Deng, W.; Song, X.; Liu, Y.; Zhang, S.; Su, Y.; Lu, Y. Spatio-temporal impact of rural livelihood capital on labor migration in Panxi, southwestern mountainous region of China. Chin. Geogr. Sci. 2018, 28, $153-166$. [CrossRef]

18. Yang, C. Rural-urban migration, rural household income and local geographical contexts-A case of northwestern Guangxi, China. Chin. Geogr. Sci. 2018, 18, 17-23. [CrossRef] 
19. Pu, Y.; Ge, Y.; Ma, R.; Huang, X.; Ma, X. Analyzing regional economic disparities based on ESDA. Geogr. Res. 2005, 24, 966-973. (In Chinese)

20. Rao, C.; Yu, J.; Zhu, H. Land ownership as an urban employment disincentive for rural migrants in China. Dev. Econ. 2015, 53, 135-149. [CrossRef]

21. Pan, Z.; Xu, W.; Huang, Z.; Wang, G. The effects of labour migration on rural household production in inland China: Do landform conditions matter? Popul. Space Place 2018, 24, e2086. [CrossRef]

22. Wang, S.X.; Benjamin, F.Y. Labor mobility barriers and rural-urban migration in transitional China. China Econ. Rev. 2018, 53, 211-224. [CrossRef]

23. Kasimis, C.; Papadopoulos, A.G.; Pappas, C. Gaining from rural migrants: Migrant employment strategies and socioeconomic implications for rural labor markets. Sociol. Ruralis 2010, 50, 258-276. [CrossRef]

24. Jokisch, B.D. Migration and agricultural change: The case of smallholder agriculture in highland Ecuador. Hum. Ecol. 2002, 30, 523-550. [CrossRef]

25. Koster, J.M.; Grote, M.N.; Winterhalder, B. Effects on household labor of temporary out-migration by male household; heads in Nicaragua and Peru: An analysis of spot-check time allocation; data using mixed-effects models. Hum. Ecol. 2013, 41, 221-237. [CrossRef]

26. Chandrasekhar, S.; Sharma, A. Urbanization and spatial patterns of internal migration in India. Spat. Demogr. 2015, 3, 63-89. [CrossRef]

27. Long, M.; Xiang, R.; Zhang, J. Village analysis of gradient urbanization: A case study of Shanghang, Fujian. Sci. Geogr. Sin. 2016, 36, 1531-1538. (In Chinese)

28. Wang, Z.Y.; Fei, J.J.; Economics, S.O. Space choice of population migration: Local urbanization or remote urbanization. Financ. Trade Res. 2014, 25, 61-67. (In Chinese)

29. Liu, S.; Xie, F.; Zhang, H.; Guo, S. Influences on rural migrant workers' selection of employment location in the mountainous and upland areas of Sichuan, China. J. Rural Stud. 2014, 33, 71-81. [CrossRef]

(C) 2019 by the authors. Licensee MDPI, Basel, Switzerland. This article is an open access article distributed under the terms and conditions of the Creative Commons Attribution (CC BY) license (http:/ / creativecommons.org/licenses/by/4.0/). 